\title{
"An art, not a science"? LIS, digital humanities, and the call to undiscipline
}

$\mathbf{T}$ he origin date of digital humanities (DH) is as contested as virtually everything else about it, but the contexts in which I first heard the term were laced with disciplinary anxiety, despair, and derision.

I'd started an English PhD amid 2009's economic doomscape, and peers on the market were seeing "digital humanities" appear in job postings in vague, seemingly incongruous ways. What did a "secondary specialization in digital humanities" entail, and how could it possibly pertain to subdisciplines spanning Medieval Studies and global Anglophone literatures and Victorian fiction? Facing this quandary, some dismissed $\mathrm{DH}$ wholesale as a gimmicky way to court STEM funding without doing any "real" humanities work, while others made Moby Dick word clouds in desperate bids to qualify themselves for those postings.

I shared (and still share) suspicions about how $\mathrm{DH}$ is sometimes invoked, but even then they also struck me-someone in queer studies, a field that itself had only relatively recently gained legitimacy_as methodologically xenophobic. Having realized professorship wasn't for me, I signed up for a summer DH internship our library was piloting. More than illuminating what DH "is," it paved my first steps toward librarianship by introducing me to people in positions I'd never known existed, performing labor that made my own disciplinary study possible. And in that process, it helped me see that "What belongs?" is usually a less generative question to ask of disciplines than "How is 'belonging' produced?" Through this lens, I now see territorial anxiety as less a bug than a feature of disciplinarity, so to speak, and I see much greater potential and urgency for $\mathrm{DH}$ and information literacy (IL) to work in tandem.
My grad school peers weren't alone in their suspicions of $\mathrm{DH}$, which have been voiced loudly and on numerous grounds. Indeed, as Andrea Baer ${ }^{1}$ notes, "much of DH literature centers on disagreements about what the digital humanities is and what it should or should not do." DH projects often replicate existing literary priorities (i.e., White, Western canon), they can exclude communities lacking tech and broadband access, and they may use quantitative data to produce a "truthier" appearance than nonempirical literary methods. Others, like Richard Grusin, ${ }^{2}$ are leery of DH's emergence "as 'the next big thing" in seeming alignment with the "neoliberalization and corporatization of higher education." But these discussions have raised questions we should be asking of all scholarly endeavors, and $\mathrm{DH}$ praxis has established new channels for scholarly creation, preservation, and information openness. The dust around these controversies has settled to the extent that $\mathrm{DH}$ has earned an enduring place on syllabi, in job ads, within libraries, and increasingly as an accepted form of production toward tenure/ promotion. However, other debates continue on Twitter, at conferences, and in publications such as Digital Humanities Quarterly, Defining Digital Humanities, and perhaps most notably the excellent Debates in the Digital Humanities series.

Coedited by Matthew K. Gold and Lauren F. Klein, Debates highlights the myriad tensions, successes, and possibilities in $\mathrm{DH}$, providing edifying accounts of the field's histories and iterations since

Lynne Stahl is Humanities librarian at West Virginia University, email: lynne.stahl@mail.wvu.edu 
the mid-1900s. Most fascinating to me are the contemplations, within and beyond this series, of the metrics and authority that would confer $\mathrm{DH}$ disciplinary legitimacy. Claire Warwick ${ }^{3}$ observes wryly that while prominent, controversial literary scholar Stanley Fish was "predictably negative about digital humanities ... that he had deigned to notice it at all seemed to be regarded. . . as an indication that the field was at last worthy of note." Citing a DH-dedicated PMLA issue, Gold and Klein ${ }^{4}$ contend, too, that "a special issue of a journal is what signals the arrival of a field." Yet mention by elite white male scholars and inclusion in prestigious journals seem a dubious scale of validation given critiques of whiteness and imperialism in DH from Kim Gallon, Alan Liu, Safiya Umoja Noble, Tara McPherson, Roopika Risam, and many more.

Strikingly absent from the $\mathrm{DH}$ origin stories and meditations on disciplinary legitimacy is a force that facilitated many of these cross-disciplinary conversations: library organizing systems. The phrase "Library of Congress Subject Headings" occurs only once across the three Debates volumes, as an example of authority control forms that can reflect cultural biases. Though "discipline(s)" and "disciplinary" occur 45 times in the 2019 volume alone, no essay mentions the creation of the "digital humanities" LCSH. ${ }^{5}$ Nor does "LCSH" appear anywhere in the 14-year run of Digital Humanities Quarterly, ${ }^{6}$ an open access journal "covering all aspects of digital media in the humanities."

While no publication can capture every perspective, Debates represents a wealth of interests and individuals, and the fact that none of its component essays even acknowledge the subject heading speaks to inherited hierarchies of visibility and recognition. LCSH function in database searches to collocate texts whose classifications might place them in entirely different physical locations. A WorldCat subject search for "digital humanities" yields results with LC classifications all over the stacks. To some degree, then, DH owes its cohesion to the LCSH for returning sets of titles that might not otherwise appear anywhere near one another, from The Digital Humanities: A Primer for Students and Teachers (AZ) to Abstract Machine: Humanities GIS (G) to Digital Humanities in the Library (Z).
Beyond wounded librarian dignity—which is not nothing-why does this omission matter? First, it marks a curious divergence between fields with remarkably similar origins. Widely regarded as one of the first literary computing projects, Father Roberto Busa's Index Thomisticus enabled automated searching within St. Thomas Aquinas' expansive oeuvre. It also replicated existing hierarchies in its object (a White man's canonical writings) and its creation (women doing manual data entry). Busa preferred women for the punchcard indexing labor, believing them "more careful" than men. Though the technical skills they learned propelled some of them into relatively good jobs, their work-which Melissa Terras and Julianne Nyhan detail in Debates 2016-went largely uncredited for decades. This scenario bears an uncanny resemblance to Melvil Dewey and Charles Cutter's favored approach of employing women for work viewed as beneath men.

Second, Melissa Adler's Cruising the Library ${ }^{8}$ illustrates how the "categories that designate what library books are about actively produce, reproduce, and privilege certain subjects and disciplinary norms," and how disciplines themselves work over time to produce particular discourses. It's thus disquieting to see cataloging and classification systems unaccounted for in these $\mathrm{DH}$ conversations - but given how little time many librarians and other academics spend explicitly discussing the emergence and constitution of the disciplines we study and teach, perhaps it's unsurprising.

I remember admittedly little about my Organization of Information class in library school. But Cutter's ${ }^{9}$ foundational admonition that "cataloging is an art, not a science" stuck in my craw for the dubious rhetorical work it does, first in investing his own contributions with an air of mystical genius and second in implying that science is intrinsically or necessarily more objective than art, that scientific analyses are unsubjective.

Indeed, he was writing at a time when many sciences (especially sexology and Darwinian evolutionary theory) were exerting great efforts to catalog order into society-a cisheteronormative, ableist, White supremacist order that manipulated "empirical" evidence into justifying its inequities. Though Library of Congress Clas- 
sification (LCC), heavily influenced by Cutter's system, is distinct from LCSH, the two operate in concert.

Analyzing the role of LIS as an agent of hegemony in shaping the disciplines, Adler invokes a question posed by philosopher Michel Foucaul $\mathrm{t}^{10}$ whose critiques of taxonomies, knowledge production, and surveillance have been integral to queer, postcolonial, and critical race theory as well as disability studies: "What types of knowledge are you trying to disqualify when you say you are a science?" Foucault's critiques center on practices that arose in the Victorian era, contemporaneous with Dewey and Cutter.

There's an intriguing inversion in the contested disciplinarities of $\mathrm{DH}$ and LIS. To what extent is library "science" a science, and what do we seek to gain through that label? To transpose Foucault's question, What types of labor are you trying to obscure when you call yourself "humanities"? The predominant view of disciplines as "turf" reflects a colonial mindset and an economy of scarcity-unsurprising, as our everyday lives are structured by both. Boundaries invite policing, and forces in power typically work to maintain power.

Rather than simple evidence of a pressing need to promote and explain LIS as a discipline, therefore, perhaps we can read this unrecognized interrelationship between DH and IL as a parable about the hazards of disciplinarity. As long as systemic inequalities exist, disciplines will be inequitably prioritized among themselves and will at once enact inequities within themselves. Recent discourses of undisciplinarity, initiated by BIPOC scholars, offer a key-imperative, I think-point of entry for LIS engagement. Championed by academics doing antiracist, decolonial, and feminist work across fields, Christina Sharpe's ${ }^{11}$ call to "become undisciplined" builds from her observation that for Black scholars, "to produce legible work in the academy often means adhering to research methods" prescribed by and in service to dominant institutional formations.

It's apropos, then, that scholars in Victorian Studies were among the first to amplify Sharpe's notion. The 19th-century subdiscipline is constructed primarily around the reign of a British monarch under whom colonialization and global capitalism boomed, during which the sexological and evolutionary sciences that shape library classifications emerged. To study 19th-century Britain is also-or should be-to take as foundational its slavery-based economy and attendant racialized hierarchies that still infuse every aspect of our lives. But that work has historically been marginalized in favor of a disciplinary narrative "fictively demarcated as nonracial," write Ronjaunee Chatterjee, Alicia Mireles Christoff, and Amy R. Wong ${ }^{12}$ in their call to "render explicit the racism that subtends the history of aesthetics, canon formation, and curricular bias."

To undiscipline isn't necessarily to jettison disciplinary boundaries, but to recognize and push against them by building their examination and critique into curricula and into IL approaches. DH and IL are well-positioned to challenge these limits: to identify and critique disciplinary bias in terms of organizational schemas, publishing norms, modes of scholarly production, and the economic contingences on which all depend. As Lincoln Mullen ${ }^{13}$ suggests, virtually all humanities scholarship now substantively engages the digital, from citation managers to text mining and data visualization to navigating the linked data that structures our research processes. "Doing” DH is less a matter of acquiring technical skills than of recognizing the sociocultural elements that comprise the digital systems through which we produce, disseminate, and seek information. In this regard, it's practically indistinguishable from critical information literacy approaches, even if these literacies aren't fully coextensive.

No organizing schema can be free of bias, and no discipline arises in a vacuum. Exploring how the two constitute each other might better address all of these issues than simply speaking more loudly on behalf of our (or any) discipline. Some in libraries are already doing this work in various ways: critical pedagogy, cataloging, information literacy; addressing archival silences and erasures; challenging coded hiring criteria.

We might strive for increasingly embedded forms, such as working with faculty in other fields to build disciplinary histories into their curricula, but also in considering job postings, 
promotion criteria, effects of increasing adjunctification on the futures of disciplines themselves, and other disciplinary boundaries that-while often invisible—are always constitutive.

\section{Acknowledgement}

Many thanks to Susan Garfinkel at the Library of Congress for assistance in tracing the history of the "Digital Humanities" Library of Congress Subject Heading.

\section{Notes}

1. Andrea Baer, "Critical Information Literacy in the College Classroom: Exploring Scholarly Knowledge Production through the Digital Humanities," in Information Literacy and Social Justice: Radical Professional Praxis, ed. Lua Gregory and Shana Higgins, (Los Angeles: Library Juice Press, 2013), 109.

2. Richard Grusin, "The Dark Side of Digital Humanities: Dispatches from Two Recent MLA Conventions," differences 25, no. 1 (May 1, 2014): 87, https://doi.org/10.1215 /10407391-2420009.

3. Claire Warwick, “'They Also Serve': What DH Might Learn about Controversy and Service from Disciplinary Analogies," in Debates in the Digital Humanities 2019, ed. Matthew K. Gold and Lauren F. Klein (Minneapolis: University of Minnesota Press, 2019), https://dhdebates. gc.cuny.edu/projects/debates-in-the-digital -humanities-2019.

4. Gold and Klein, "Introduction: A DH That Matters," in Debates 2019.

5. A genealogy of the LCSH-est. 2008would be a fascinating undertaking. For this essay's purposes its absence from DH literature suffices.

6. "DHQ: Digital Humanities Quarterly: About," accessed April 9, 2021, http://digitalhumanities.org: $8081 /$ dhq /about/about.html.

7. Melissa Terras and Julianne Nyhan, "Father Busa's Female Punch Card Operatives," in Debates in the Digital Humanities 2016, ed. Gold and Klein (Minneapolis: University of Minnesota Press, 2016), https://dhdebates.gc.cuny.edu/read /untitled/section/ 1 e 57217 b-f262-4f25 -806b-4fcf1548beb5.

8. Melissa Adler, Cruising the Library: Perversities in the Organization of Knowledge (New York: Fordham University Press, 2017), 2.

9. Charles Cutter, Rules for a Dictionary Catalog, U.S. Government Printing Office, 1904.

10. Michel Foucault, Society Must Be Defended: Lectures at the Collège de France, 1975-76, ed. Mauro Bertani and Alessandro Fontana, trans. David Macey (New York: Picador, 2003), 2, qtd. in Adler, 23.

11. Christina Sharpe, In the Wake: On Blackness and Being (Durham: Duke University Press, 2016), 13.

12. Ronjaunee Chatterjee, Alicia Mireles Christoff, and Amy R. Wong, "Undisciplining Victorian Studies," Los Angeles Review of Books, July 10, 2020, https://lareviewofbooks.org /article/undisciplining-victorian-studies/.

13. Lincoln Mullen, "Digital Humanities Is a Spectrum; or, We're All Digital Humanists Now," April 29, 2010, https://lincolnmullen. $\mathrm{com} / \mathrm{blog} /$ digital-humanities-is-a-spectrum-or -we8217re-all-digital-humanists-now/. ュ

("Mentoring each other," continued from page 476)

nections and reinforced trust among the group members. Whether we are exploring new ideas, struggling with current challenges, or bouncing new ideas off each other, we always find our time together to be well spent. We hope you can find a similar community that will help you thrive.

\section{Notes}

1. Etienne Wenger, Richard McDermott, and
William M. Snyder, Cultivating communities of practice: A guide to managing knowledge (Boston, Mass: Harvard School Press, 2002), 9.

2. Etienne Wenger-Trayner and Beverly WengerTrayner, "Introduction to communities of practice: A brief overview of the concept and its uses," WengerTrayner, https://wenger-trayner.com/introductionto-communities-of-practice/ (accessed May 28, 2021). 